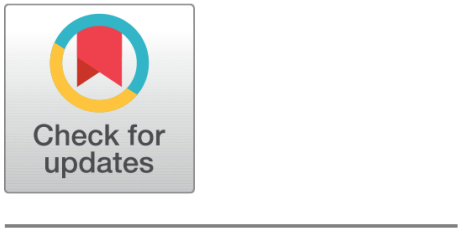

OPEN ACCESS

Received: 10.09.2021

Accepted: 11.10 .2021

Published: 03.11 .2021

Citation: Malathi G, Vadivelu J, Rajeshkumar S (2021) Antioxidant Revival of Cucumis melo I. Modulates the Oxidant-antioxidant Status on Chromium VI Toxicity Induced Male Albino Rats. Indian Journal of Science and Technology 14(36): 2815-2825. https://doi.org/ 10.17485/IJST/v14i36.1688

* Corresponding author.

vadivelu2015@gmail.com

Funding: None

Competing Interests: None

Copyright: ๑ 2021 Malathi et al. This is an open access article distributed under the terms of the Creative Commons Attribution License, which permits unrestricted use, distribution, and reproduction in any medium, provided the original author and source are credited.

Published By Indian Society for Education and Environment (iSee)

ISSN

Print: 0974-6846

Electronic: 0974-5645

\section{Antioxidant Revival of Cucumis melo I. Modulates the Oxidant-antioxidant Status on Chromium VI Toxicity Induced Male Albino Rats}

\author{
Gangadharan Malathi ${ }^{1}$, Jayavelu Vadivelu' ${ }^{2 *}$, Shanmugam Rajeshkumar ${ }^{3}$ \\ 1 Research Scholar, Post Graduate and Research Department of Biochemistry, Sri \\ Akilandeswari Women's College, Wandiwash, 604408, Tamil Nadu, India \\ 2 Assistant Professor, Post Graduate and Research Department of Biochemistry, Sri \\ Akilandeswari Women's College, Wandiwash, 604408, Tamil Nadu, India \\ 3 Nanobiomedicine lab, Department of Pharmacology, Saveetha Dental College and \\ Hospitals, Saveetha University, SIMATS, Chennai, 600077, TN, India
}

\section{Abstract}

Objective: To assess the natural bio-remediation in Hexavalent chromium $(\mathrm{Cr} \mathrm{VI})$ toxicity induced rats. Methodology: Male albino rats were given Hexavalent chromium for 42 days to demonstrate that this carcinogenic compund increased LPO while reducing SOD, GSH, GPx, and CAT levels. Rats were randomly divided into five experimental groups $(n=6)$. Group I was a control group as they were only given with clean water to drink. Potassium dichromate $10 \mathrm{~g} / \mathrm{kg}$ was given to Group II for 42 days. Group III administered with $500 \mathrm{mg} / \mathrm{kg}$ of Cucumis melo L, Group IV was administered with $500 \mathrm{mg} / \mathrm{kg}$ of Ascorbic acid and Group V was administered with 1:1 ratio of Cucumis melo $\mathrm{L}$ and ascorbic acid, respectively. All results were provided as mean SD for a total of 6 rats/ per each group. The significance of differences between male albino rats was determined using the Student's t-test. At $p<$ 0.05 and $p<0.001$, differences were judged significant. Findings: Cucumis melo L. fruit aqueous extracts significantly protected rats from chromiuminduced oxidative damage. The LD50 was determined to be $500 \mathrm{mg} / \mathrm{kg}$ using the DPPH assay. As a consequence, we believe that giving fruit extracts to people can help them recover from oxidative stress-related cell damage. Novelty: The administration of chromium 6 resulted in a substantial reduction in body weight and an increase in the organ to body weight ratio. Chromium administration significantly enhanced LPO while decreasing serum levels of SOD, GSH, GPx, and CAT. Cucumis melo aqueous fruit extract was shown to be a protective agent against chromium-induced oxidative stress at a dosage of $500 \mathrm{mg} / \mathrm{kg}$.

Keywords: Chromium Vl; Cucumis melo L fruit extracts; antioxidant activity; oxidant antioxidant imbalance and oxidative stress 


\section{Introduction}

Antioxidant components such as phenolics, vitamins, carotenoids, and minerals are found in the fruits (name them), which contribute to their chemopreventive potential. ${ }^{(1,2)}$ All of these chemicals have been linked to a reduced chance of developing health issues such as cancer, cardiovascular disease, type 2 diabetes, and obesity.

During the growth of melons, volatile and antioxidant chemicals will generate and develop. ${ }^{(3)}$ The ripening stage has been shown to have a significant impact on the amounts of high bioactive chemicals in fruits. $(4,5)$ The study of bioactive chemical changes during fruit ripening is important for both human health and economic interests. These findings are useful in determining how those chemicals change over time and determining the optimal harvesting period to obtain the maximum antioxidant potential. Harvesting at the right time ensures a high-quality fruit with great nutritional value.

Because of its low molecular weight, hydroxycinnamic acid (caffeic, sinapic, -coumaric, and ferulic acids) is an important product of phenyl propanoid. They are commonly associated with polysaccharides found in cell walls, particularly lignin and heratsllulose units. Because of their existence in vegetables, phenolic acids, such as flavonoids, are extensively dispersed in nature and are linked to defensive functions and taste appeal. The flavonoids are connected to the polysaccharides of the cell wall, which include lignin and heratsllulose. ${ }^{(6)}$

Tannins include phosphorus and antioxidants. Polyphenols, which are made up of phenolic acids, flavonoids, and hydrolyzable tannins, have anti-proliferative properties. Many research have looked at the complex connections between reactive oxygen production, carcinogenesis, and cellular damage. Radiation, iron excess, inflammation, UV light, and different carcinogenic substances all cause an increase in oxidative stress in bacteria. The tip of the iceberg of carcinogenesis is oxidative stress. ${ }^{(7,8)}$

Cucumis trigonus Roxb. is a perennial tendrillar plant of the Cucurbitaceae family. It is endemic to India and may be found across the country, as well as in Ceylon, Afghanistan, Persia, and Northern Australia. C. trigonus root, fruit, and seeds have great therapeutic significance in traditional medicine. The plant's roots are used as a purgative and liver tonic. The fruits are used to cure leprosy, fever, jaundice, diabetes, cough, bronchitis, anaemia, constipation, and other gastrointestinal problems, as well as amentia. ${ }^{(9)}$ Antioxidants, phenolic substances, and antiproliferative properties are all evaluated. Extracts of melon residues were produced, and antioxidant activity was assessed. The phenolic chemicals are found in the hydroethanolic, hydroethanolic, aqueous extract of the melon peel. The melon seeds contain gallic acid at a value of $1.016 \mathrm{mg} / 100 \mathrm{~g}$. Melon peel aqueous extract includes flavonoids, including Catechin $262 \mathrm{mg} / 100 \mathrm{~g} .{ }^{(10)} \mathrm{In}$ addition, fruit pulp is bitter, acrid, thermogenic, anthelmintic, liver tonic, cardio tonic, appetizer, expectorant and intellect promoting

In terms of antioxidant activity, the equivalent of ascorbic acid in fruit is 74 percent hydroethanolic and 89 percent hydroethanolic, respectively, whereas seeds contain 83 percent hydroethanolic. The aqueous extract of melon peel has 84 percent copper and 61 percent iron, and different quantities of melon extracts exhibit iron and copper chelating activity. The hydroethanolic melon peel extract exhibits a 68 percent hydroxyl radical scavenging activity. ${ }^{(10)}$ Hence, our present work aims to investigate the modulation of oxidant-antioxidant status by fruit extract of C. melo L. on Hexavalent chromium- induced toxicity in male albino rats.

\section{Materials and Method methodology was not in detail}

\subsection{Collection and Authentication of Plant}

C. melo L. fruits were collected from Vandavasi, Thiruvannamalai, District, Tamil Nadu in India. All plant materials were collected from the months of December to January 2019-2020. Fruits were authenticated by the Siddha Central Research Institute, Chennai (Central Council for Research in Ayurveda and Siddha, New Delhi, Under the Ministry of Health \& Family Welfare, Govt. of India), Reference No: C14022001M.

\subsection{Preparation of Plant Extract}

Whole ripened fruit with seeds were shade dried for 3 days. Extraction was carried out by methodology of Azevedo Martins TE et al., ${ }^{(11)}$ at room temperature under normal conditions. About $100 \mathrm{~g}$ of shade dried powder of fruits of C. melo L. was successively extracted with absolute methanol $(1000 \mathrm{ml})$ by Soxhlet Extraction. The extract obtained was filtered with sterile cotton cloth. Final concentration obtained after extraction as [100g/l].

Potassium Dichromate $\left(\mathbf{K}_{2} \mathbf{C r}_{2} \mathbf{O}_{7}\right)$ was purchased from scientific Lab Chemicals, Chennai (99.9\%). 


\subsection{Phytochemical screening and Dosage analysis:}

\section{Gas Chromatography-Mass Spectrometry (GC-MS) Analysis:}

Fruit extract were subjected to GC-MS analysis using the model instrument, GCMS-QP2010 Ultra (Shimadzu Co., Japan) attached with a capillary column DB-1 (0.25 [micro]m film x $0.25 \mathrm{~mm}$ I.d. $30 \mathrm{~m}$ length). Analysis was performed by injecting $1 \mu \mathrm{L}$ of the sample with a split ratio of 20:1, and Helium gas (99.9\%) was used as the carrier gas at a flow rate of $1 \mathrm{~mL} / \mathrm{min}$.

The ability of C. melo fruit extract to scavenge hydrogen peroxide was determined (provide citation). An aliquot of $0.6 \mathrm{ml}$ of hydrogen peroxide $(43 \mathrm{Mm})$ and $1.0 \mathrm{ml}$ of various concentration of extracts prepared using phosphate buffer $(100-500 \mathrm{mg} / \mathrm{ml})$ were mixed, followed by $2.4 \mathrm{ml}$ of $0.1 \mathrm{M}$ phosphate buffer $\left(\mathrm{p}^{\mathrm{H}}\right.$ 7.4). The resulting solution was kept for $10 \mathrm{~min}$ and the absorbance was recorded at $230 \mathrm{~nm}$. All measures were repeated triplicate. For each concentration mixture without sample was taken as a control and mixture without hydrogen peroxide was taken as a blank. Ascorbic acid was used as a standard compound. The percentage scavenging of hydrogen peroxide was calculated as: ${ }^{(12)}$

$$
\text { Scavenging activity }(\%)=(\mathrm{A} 0-\mathrm{As}) / \mathrm{A} 0 \mathrm{X} 100
$$

Where $\mathrm{A} 0$ is the absorbance of the control As is the absorbance of the sample

\subsection{Animal \& Maintenance Condition}

Rats:

Rats weighing 160 - $180 \mathrm{~g}$ were obtained from the Biomedical Research Unit and Laboratory Animal Centre, BRILAC/SDCH/SIMATS/IAEC/3-2020/049 Chennai and maintained according to the guidelines of CPCSEA under the supervision of Animal Ethical Committee. All animals were housed under standard conditions $\left(25 \pm 1{ }^{\circ} \mathrm{C}, 12 \mathrm{~h}\right.$ light/12 h dark cycle) with food and water ad libitum and were acclimated to the laboratory conditions for 7 days prior to starting the experiment.

\subsubsection{Experimental design}

Male albino rats were divided into five groups; each group consists of six animals $(n=6)$. Different groups with different doses were given below:

\begin{tabular}{ll}
\hline Groups & Doses \\
\hline Group I & Control [water] \\
Group II & Potassium dichromate $[10 \mathrm{mg} / \mathrm{kg}]$ \\
Group III & $500 \mathrm{mg} / \mathrm{kg}$ of Cucumis melo $\mathrm{L}$ \\
Group IV & $500 \mathrm{mg} / \mathrm{kg}$ of Ascorbic acid \\
Group V & $500 \mathrm{mg} / \mathrm{kg}$ of Cucumis melo $\mathrm{L}+500 \mathrm{mg} / \mathrm{kg}$ of Ascorbic acid [1:1] \\
\hline
\end{tabular}

Body weight of all the animals was recorded during 0 th $, 10^{\text {th }}, 20^{\text {th }}, 30^{\text {th }}, 42^{\text {nd }}$ and $49^{\text {th }}$ days respectively.

\subsection{Hydroxyl Radical (OH) Scavenging Activity}

Hydroxyl radical scavenging activity was determined by method as described by Rolim PM et al., ${ }^{(13)}$. The ability of C. melo L.to scavenge the hydroxyl radicals generated was determined. The reaction mixture containing $100 \mu \mathrm{L}$ of $28 \mathrm{mM} 2$-deoxy-2ribose in $100 \mu \mathrm{L}$ of $200 \mu \mathrm{M} \mathrm{FeCl}_{3}, 100 \mu \mathrm{L}$ of $1.04 \mathrm{mM}$ EDTA (phosphate buffer $\mathrm{pH} 7.4$ ), $100 \mu \mathrm{L}$ of $1 \mathrm{mM} \mathrm{H}_{2} \mathrm{O}_{2}, 100 \mu \mathrm{L}$ of $1 \mathrm{mM}$ Ascorbic acid and $100 \mu \mathrm{L}$ of test samples (aqueous extract of C. melo L.) were incubated at $37 \mathrm{oC}$ for $1 \mathrm{hr}$. Later $1.5 \mathrm{~mL}$ of $20 \%$ acetic acid, $1.5 \mathrm{~mL}$ of $0.8 \%$ TBA was added and the tubes are kept at $95^{\circ} \mathrm{C}$ for $30 \mathrm{mins}$. The resultant mixture was allowed to cool to room temperature and the absorbance was recorded at $540 \mathrm{~nm}$ in UV-Visible spectrophotometer and vitamin $\mathrm{E}$ was used as a standard.

\subsection{Preparation of Tissue Homogenates}

Freshly excised Liver and Kidney was washed in cold saline $(0.9 \% \mathrm{NaCl})$, blotted dry, dropped into a cold beaker and minced well with scissors. Then $0.25 \mathrm{M}$ ( $8 \mathrm{ml}$ per gram wet weight) sucrose solution was add and homogenized. Then the homogenate was filtered and centrifuged at $5000 \mathrm{rpm}$ for $10 \mathrm{~min}$. The pellet was re-homogenized and resuspended as before. The supernatants were combined and centrifuged again at $15,000 \mathrm{rpm}$ for $20 \mathrm{~min} .{ }^{(14)}$ 


\subsection{Oxidant and Antioxidant Status}

\subsubsection{Lipid peroxide (LPO)}

The tissues are homogenized in $0.1 \mathrm{M}$ buffer $\mathrm{pH} 7.4$ with a Teflon-glass homogenizer. LPO in this homogenate is determined by measuring the amounts of malondialdehyde (MDA) produced primarily. Tissue homogenate $(0.2 \mathrm{~mL}), 0.2 \mathrm{~mL}$ of $8.1 \%$ sodium dodecyl sulfate (SDS), $1.5 \mathrm{~mL}$ of $20 \%$ acetic acid and $1.5 \mathrm{~mL}$ of $8 \%$ TBA are added. The volume of the mixture is made up to $4 \mathrm{~mL}$ with distilled water and then heated at $95^{\circ} \mathrm{C}$ on a water bath for $60 \mathrm{~min}$ using glass balls as condenser. After incubation the tubes are cooled to room temperature and final volume was made to $5 \mathrm{~mL}$ in each tube. Five $\mathrm{mL}$ of butanol: pyridine (15:1) mixture is added and the contents are vortexed thoroughly for $2 \mathrm{~min}$. After centrifugation at $3000 \mathrm{rpm}$ for $10 \mathrm{~min}$, the upper organic layer is taken and its OD is taken at $532 \mathrm{~nm}$ against an appropriate blank without the sample. The levels of lipid peroxides can be expressed as $\mathrm{n}$ moles of thiobarbituric acid reactive substances (TBARS)/mg protein using an extinction coefficient of $1.56 \times 10^{5} \mathrm{ML} \mathrm{cm}^{-1}$. Waseem, $\mathrm{M}$ et al., ${ }^{(15)}$

\subsubsection{Superoxide Dismutase activity (SOD)}

The partially purified superoxide dismutase was prepared as described by McCord and Bishwajit Kumar et al., ${ }^{(16)}$ To $1 \mathrm{ml}$ of the tissue homogenate, $0.25 \mathrm{ml}$ of absolute ethanol and $0.15 \mathrm{ml}$ of chloroform were added. After $15 \mathrm{~min}$ of shaking in a mechanical shaker, the suspension was centrifuged and the supernatant obtained constituted the enzyme extract. The reaction mixture for auto oxidation consisted of $2 \mathrm{ml}$ of the buffer containing DETAPAC, $0.5 \mathrm{ml}$ of $2 \mathrm{mM}$ pyrogallol and $1.5 \mathrm{ml}$ of water. Initially, the rate of auto oxidation of pyrogallol was noted for 3 minutes at an interval of every minute. The assay mixture for the enzyme contained $2 \mathrm{ml}$ of $0.05 \mathrm{M}$ TrisHCl buffer, $0.5 \mathrm{ml}$ of pyrogallol, aliquot of the enzyme preparation and water to give a final volume of $4 \mathrm{ml}$. The rate of inhibition of pyrogallol auto oxidation after the addition of the enzyme was noted. The enzyme activity was expressed in terms of units per $\mathrm{ml}$ of haemolysate and units per mg protein in the tissues. One unit corresponds to the amount of enzyme that inhibited the auto oxidation reaction by $50 \%$.

\subsubsection{Glutathione peroxide (GPX)}

The activity of glutathione peroxidase was determined by ${ }^{(17)}$ Adding $0.4 \mathrm{ml}$ of buffer, $0.1 \mathrm{ml}$ of sodium azide, $0.2 \mathrm{ml}$ of reduced GSH, $1 \mathrm{ml}$ of tissue homogenate, $0.1 \mathrm{ml}$ hydrogen peroxide and distilled water were taken in a final incubation volume of 2.0 $\mathrm{ml}$. The tubes were incubated at $37^{\circ} \mathrm{C}$ for 3 minutes. The reaction was stopped by adding $0.5 \mathrm{ml}$ of $10 \% \mathrm{TCA}$. To determine the residual glutathione content, the supernatant was removed by centrifugation and to this $3 \mathrm{ml}$ of disodium hydrogen phosphate; $1 \mathrm{ml}$ of DTNB reagent was added. The colour developed was read at $412 \mathrm{~nm}$. A blank was treated with only disodium hydrogen phosphate and $1 \mathrm{ml}$ of DTNB reagent. Suitable aliquot of standards were taken and treated similarly. The activity of glutathione peroxidase was expressed as $\mathrm{mg}$ of GSH utilized per min per $\mathrm{ml}$ of haemolysate and $\mathrm{mg}$ of GSH per min per mg protein in tissues.

\subsubsection{Total Reduced Glutathione (GSH)}

The total reduced glutathione content was determined by adding ${ }^{(18)} 1 \mathrm{ml}$ of the homogenate was taken and the proteins were precipitated with $5 \%$ TCA. The solution was mixed well and centrifuged. To $0.5 \mathrm{ml}$ of supernatant, $2 \mathrm{ml}$ of phosphate solution was added followed by $0.5 \mathrm{ml}$ of DTNB reagent. The yellow colour developed was read at $412 \mathrm{~nm}$ in a spectrophotometer against a blank containing 5\% TCA instead of the sample. A series of standards were treated in a similar manner. The amount of glutathione in the tissue was expressed as $\mathrm{mg}$ of GSH per mg tissue.

\subsubsection{Catalase activity (CAT)}

$0.02 \mathrm{ml}$ of homogenate was added to $4 \mathrm{ml}$ of phosphate buffer. To this $1 \mathrm{ml}$ of $30 \mathrm{mM}$ of $\mathrm{H}_{2} \mathrm{O}_{2}$ was added to start the enzyme reaction. The decrease in absorbance was measured at $240 \mathrm{~nm}$ at 15 seconds interval for $3 \mathrm{~min}$ in UV-Spectrophotometer. ${ }^{(19)}$ The enzyme blank was run simultaneously with $1 \mathrm{ml}$ of distilled water instead of $\mathrm{H}_{2} \mathrm{O}_{2}$ in case of blank. The activity of catalase in homogenate is expressed as $\mu$ moles of $\mathrm{H}_{2} \mathrm{O}_{2}$ utilized/ $\mathrm{min} / \mathrm{mg}$ protein.

\section{Statistical Analysis}

Data were analyzed using statistical software package version (SPSS) 7.0. Student's t-test was used to ascertain the significance of variations between male albino rats. All data were presented as mean $\pm S D$ of $n=6$. Differences were considered significant at $\mathrm{p}<0.05, \mathrm{p}<0.01$ and $\mathrm{p}<0.001$. 


\section{RESULTS}

The scavenging activity of Cucumis melo L in a dosage dependent manner was characterized by increasing scavenging activity with varying concentrations of C. melo L. such as $100 \mathrm{mg} / \mathrm{ml}, 200 \mathrm{mg} / \mathrm{ml}, 300 \mathrm{mg} / \mathrm{ml}, 400 \mathrm{mg} / \mathrm{ml} \mathrm{and} \mathrm{500mg/ml} \mathrm{of} \mathrm{aqueous}$ extract.

GC-MS analysis revealed that the aqueous extract of whole fruit contains, 14 compounds. The identified compounds of whole fruit extracts are given in Table 1, Figure 1.

Table 1. Main compounds as analysed in GCMS

\begin{tabular}{lll}
\hline Retention time & Area\% & Phytocompounds \\
\hline 11.21 & 0.33 & Flavanoids \\
14.87 & 0.43 & Tannins \\
23.75 & 0.74 & Catechin \\
28.19 & 0.81 & Polyphenols \\
\hline
\end{tabular}

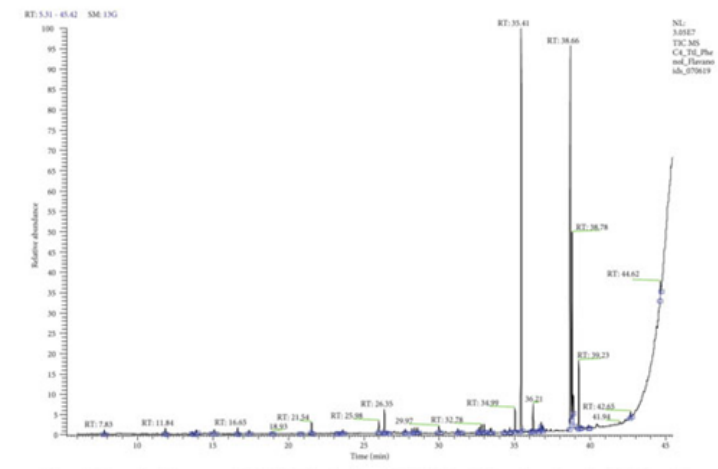

Fig 1. GCMS analysis of Cucumis melo fruit extract

The extracts were more effective in the $50 \mathrm{mg} / \mathrm{ml}$ of methanolic extract, which depicts that the $C$. melo L. exhibited strongest Hydroxyl radical scavenging activity when compared to the ethanolic and chloroform extracts respectively. Standard (Vitamin E) was taken as control showed highest antioxidant power in the present study. Hence standardization of plant extracts was indicated in our laboratory for $500 \mathrm{mg} / \mathrm{ml}$ incubation was most effective to quantify the further experiments. $C$. melo scavenges $70.85 \%$ of hydrogen peroxide in $500 \mathrm{mg} / \mathrm{ml}$, which was determined to be the necessary concentration for antioxidant action. As a result, this dosage is labelled as lethal [LD50]. [Figure 2] Previous research [20] has put the scavenging activity around 50\%, however the current study found that entire fruit may achieve a scavenging activity of around 71 percent. Improved antioxidant activity as a result of the synergistic actions of fruit components.

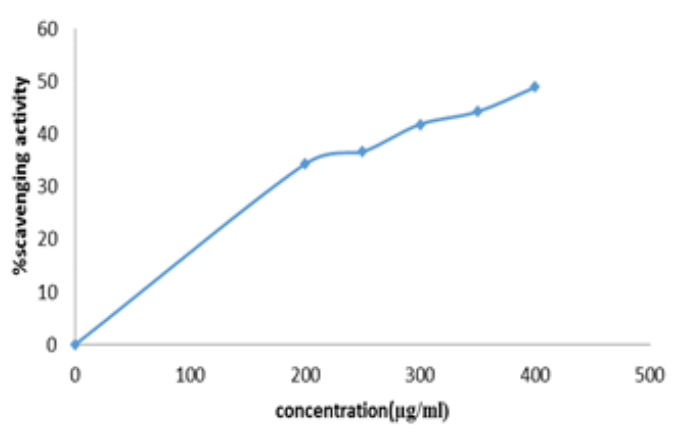

Fig 2. Antioxidant activity - in vitro 


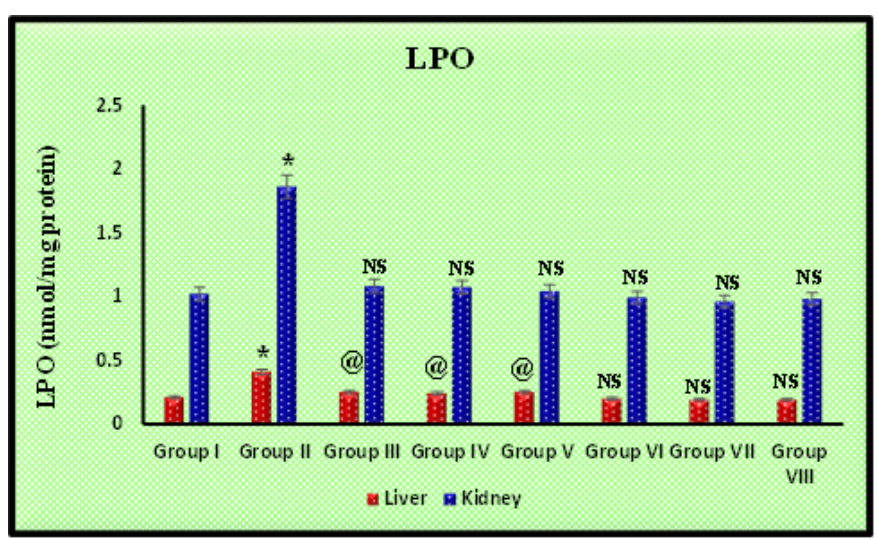

Fig 3. Changes in Liver-LPO \& Kidney-LPO of rats treated with PDC, Cucumis melo L. and Ascorbic acid. (Values represent mean \pm SD of six animals ${ }^{@} \mathrm{P}<0.05,{ }^{\$} \mathrm{P}<0.01,{ }^{\star} \mathrm{P}<0.001$ when compared to $49^{\text {th }}$ days animals)

To assess the levels of liver-LPO and kidney-LPO treatment with PDC toxicity, Ascorbic acid and aqueous extract of 500mg of C. melo L. fruit extracts were depicted in the Figure 3. The level of liver-LPO and kidney-LPO were significantly increased by 95\% and $82 \%$ in PDC induced rats when compared with control rats. Subsequently treatment with PDC induced rats along with standard Ascorbic acid the level of liver-LPO and kidney-LPO were insignificantly increased by $19 \%$ and $6 \%$ when compared with control rats. Indeed, treatment with PDC induced rats along with C. melo L fruit extracts depict the level of liver-LPO and kidney-LPO were insignificantly increased by $14 \%$ and $5 \%$ when compared with control rats. Afterwards treatment with PDC toxicity, Ascorbic acid and Cucumis melo L fruit extracts the level of liver-LPO and kidney-LPO were insignificantly increased by $19 \%$ and $2 \%$ when compared with control animal. Finally, 500g of Ascorbic acid and 500g of Cucumis melo L.fruit extracts and equal concentrations of Ascorbic acid and Cucumis melo L.fruit extracts [1:1] show that there are no significant changes in LPO levels in both organs (liver and kidney). As a result, it is proven that the fruit extract may repair oxidative stress-induced cell damage, and the impact was comparable when compared to control animals. ${ }^{(20)}$

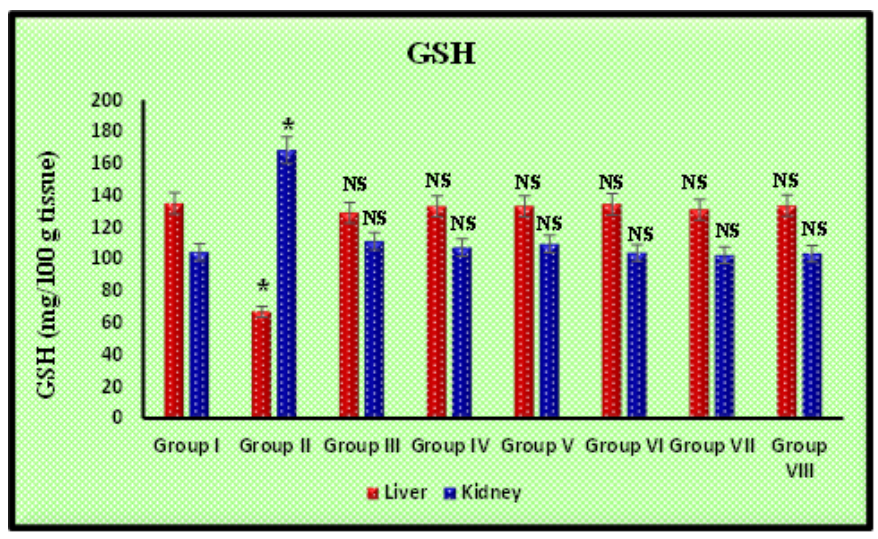

Fig 4. Changes in Liver-GSH\& Kidney-GSH of rats treated with PDC, Cucumis melo L.and Ascorbic acid. (Values represent mean \pm SD of six animals ${ }^{\circledR} \mathrm{P}<0.05,{ }^{\$} \mathrm{P}<0.01,{ }^{\star} \mathrm{P}<0.001$ when compared to $49^{\text {th }}$ days animals)

To assess the levels of liver-GSH and kidney-GSH therapy with PDC toxicity, Ascorbic acid and an aqueous extract of 500mg of C. melo L. fruit extract were used, as shown in Figure 4. The level of liver-GSH and kidney-GSH were significantly decreased by $50 \%$ and $62 \%$ in PDC induced rats when compared with control rats. Subsequently treatment with PDC induced rats along with standard Ascorbic acid the level of liver-GSH and kidney-GSH were insignificantly decreased by $4 \%$ and $6 \%$ when compared with control rats. Indeed, treatment with PDC induced rats along with C. melo L. fruit extract interpreted the level of liver-GSH and kidney-GSH were insignificantly decreased by $1 \%$ and $2 \%$ when compared with control rats. Afterwards treatment with PDC toxicity, Ascorbic acid and C. melo L. fruit extract the level of liver-GSH and kidney-GSH were insignificantly decreased 
by $4 \%$ and $1 \%$ when compared with control animal. ${ }^{(21)}$ Then quantify the standard Ascorbic acid, fruit extracts of $C$. melo $\mathrm{L}$ and equal volume of Ascorbic acid along with. melo L. represents that the there is no significant changes in level of GSH in both the organs (liver and kidney).

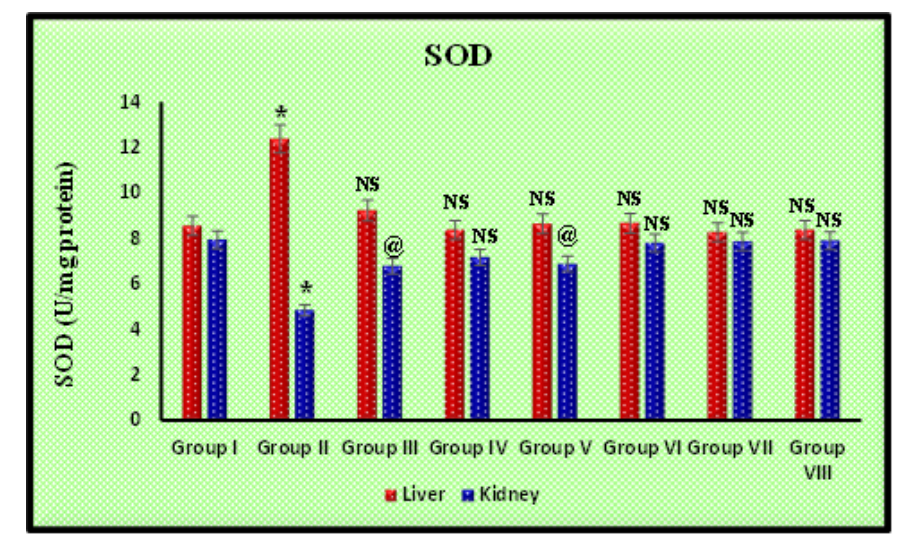

Fig 5. Changes in Liver-SOD \& Kidney-SOD of rats treated withPDC, Cucumis melo L. and Ascorbic acid. (Values represent mean \pm SD of six animals ${ }^{@} \mathrm{P}<0.05,{ }^{\$} \mathrm{P}<0.01,{ }^{*} \mathrm{P}<0.001$ when compared to $49^{\text {th }}$ days animals)

To assess the levels of liver-SOD and kidney-SOD treatment with PDC toxicity, Ascorbic acid and aqueous extract of 500 mg of C. melo L. fruit extract depicts in the Figure 5. The level of liver-SOD and kidney-SOD were significantly decreased by $45 \%$ and $40 \%$ in PDC induced rats when compared with control rats. Subsequently treatment with PDC induced rats along with standard Ascorbic acid the level of liver-SOD and kidney-SOD were insignificantly decreased by $7 \%$ and $8 \%$ when compared with control rats. Indeed, treatment with PDC induced rats along with C. melo L.fruit extracts depicts the level of liver-SOD and kidney-SOD were insignificantly decreased by $2 \%$ and $9 \%$ when compared with control rats. Afterwards treatment with PDC toxicity, Ascorbic acid and Cucumis melo L. fruit extract the level of liver-SOD and kidney-SOD were insignificantly decreased by $2 \%$ and $1 \%$ when compared with control animal. In contrast, Biswajit et al., 2020 comparie control animals to C. melo L. fruit extract, the levels of liver-SOD and kidney-SOD were insignificantly reduced by $3 \%$ and $1.5 \%$, respectively. ${ }^{(22)}$ Then quantify the standard Ascorbic acid, fruit extract of Cucumis melo L and equal volume of Ascorbic acid along with C. melo L. renderthat the there is no significant changes in level of SOD in both the organs (liver and kidney).

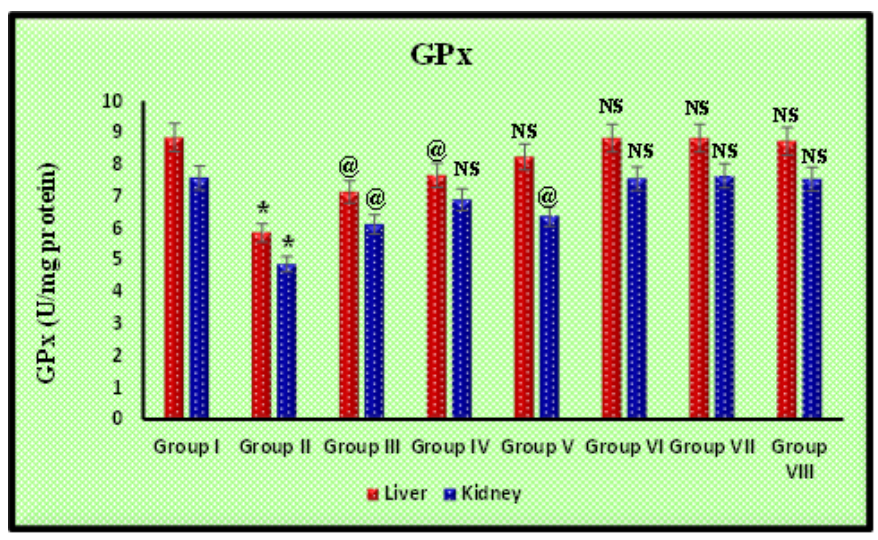

Fig 6. Changes in Liver-GPx\& Kidney-GPx of rats treated withPDC, Cucumis melo L.and Ascorbic acid. (Values represent mean \pm SD of six animals ${ }^{\circledR} \mathrm{P}<0.05,{ }^{\$} \mathrm{P}<0.01,{ }^{*} \mathrm{P}<0.001$ when compared to $49^{\text {th }}$ days animals)

To assess the levels of liver-GPx and kidney-GPx treatment with PDC toxicity, Ascorbic acid and aqueous extract of 500mg of C. melo L.f ruit extracts depict in the Figure 6. The level of liver-GPx and kidney-GPxwere significantly decreased by 33\% and 36\% in PDC induced rats when compared with control rats. Subsequently treatment with PDC induced rats along with standard Ascorbic acid the level of liver-GPx and kidney-GPxwere insignificantly decreased by $19 \%$ and $19 \%$ when compared with control rats. Indeed, treatment with PDC induced rats along with C. melo L. fruit extract depicts the level of liver-GPx and 
kidney-GPxwere insignificantly decreased by $13 \%$ and $9 \%$ when compared with control rats. Afterwards treatment with PDC toxicity, Ascorbic acid and Cucumis melo L.fruit extract the level of liver-GPx and kidney-GPx were insignificantly decreased by $7 \%$ and $16 \%$ when compared with control animal. Finally determine the 500mg of Ascorbic acid, 500mg of. melo L. fruit extracts and equal concentration of Ascorbic acid along with C. melo L. fruit extract depicts that the there is no significant changes in level of GPx in both the organs (liver and kidney). ${ }^{(23,24)}$

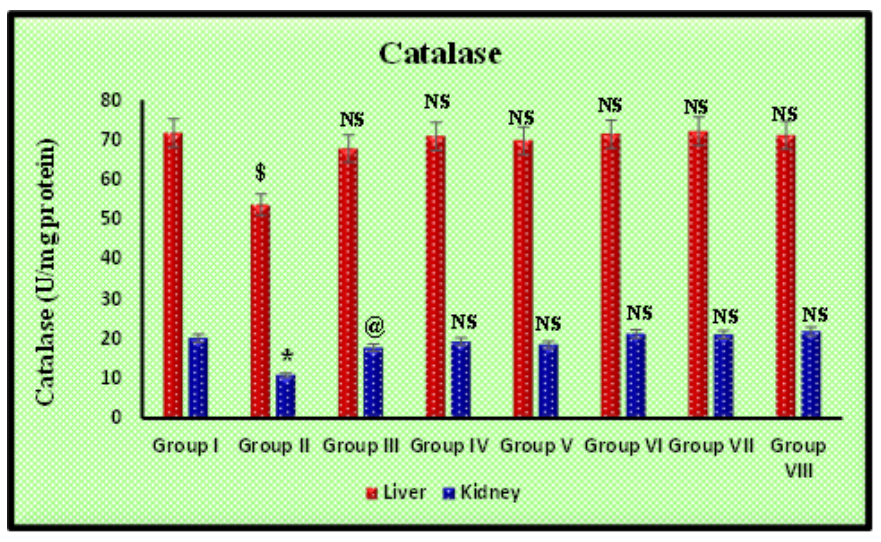

Fig 7. Changes in Liver-Catalase \& Kidney-Catalase of rats treated with PDC, Cucumis melo L. and Ascorbic acid. (Values represent mean \pm $\mathrm{SD}$ of six animals ${ }^{@} \mathrm{P}<0.05,{ }^{\$} \mathrm{P}<0.01,{ }^{*} \mathrm{P}<0.001$ when compared to $49^{\text {th }}$ days animals)

The levels of liver-Catalase and kidney-Catalase therapy with PDC toxicity were evaluated using Ascorbic acid and an aqueous extract of $500 \mathrm{~g}$ of C. melo L. fruit extract, as shown in Figure 7. The level of liver-catalase and kidney-catalase were significantly decreased by $25 \%$ and $46 \%$ in PDC induced rats when compared with control rats. Subsequently treatment with PDC induced rats along with standard Ascorbic acid the level of liver-catalase and kidney-catalase were insignificantly decreased by $5 \%$ and $12 \%$ when compared with control rats. Indeed, treatment with PDC induced rats along with C. melo L. fruit extract interpreted the level of liver-catalase and kidney-catalase were insignificantly decreased by $1 \%$ and $4 \%$ when compared with control rats. Afterwards treatment with PDC toxicity, Ascorbic acid and Cucumis melo L.fruit extract the level of liver-catalase and kidney-catalase were insignificantly decreased by $3 \%$ and $8 \%$ when compared with control animal. ${ }^{(25)}$ Then quantify the standard Ascorbic acid, fruit extracts of C. melo L.and equal volume of Ascorbic acid along with C. melo L. representsthat the there is no significant changes in level of GSH in both the organs (liver and kidney).

\section{DISCUSSION}

Phenolics, tannins and flavonoids are secondary plant metabolites that can be involved in complex system of antioxidant defense through free radical scavenging activity, chelation of transition metals and inhibition of prooxidative enzymes. They are also useful in the treatment of numerous illnesses caused by the uncontrolled production of free radicals, such as inflammatory disorders, cardiovascular disease, cancer, and diabetes.

We discovered four phenolic and flavonoid phytocontents in a retention peak of GCMS. The remaining ten phytocontents appeared to be the same, although this has yet to be validated. Rolim P M et al. ${ }^{(26)}$ used (HPLC-DAD) to identify nine phenolic compounds in seeds methanolic extract, which might explain the richness of seeds ethanolic extract in this study by polyphenols.

In addition to compilation of various methods related to evaluation of antioxidant activity, it was our interest to see the frequency of each method. Out of all the in vitro methods, DPPH is the most easy, simple and reasonably costly method and hence it might have been used mostly for the antioxidant activity evaluation of a sample. By conclusion $500 \mathrm{mg} / \mathrm{ml}$ of extract were determined as lethal dose. Hence, it is used further for in vivo studies. Lipid is a major component of cell membrane and thus its peroxidation almost directly co-relates peroxidative damage of cell in vivo and hence it might have been found to have the highest frequency in vivo antioxidant activity assay. Therefore, the following methodology was carried out by the $C$. melo L. fruit aqueous extracts to regulates the defence mechanism against oxidative stress induced cytotoxicity on rats.

The purpose of this study was to describe the oxidative state of the liver and kidney during potassium dichromate exposure (Hexavalent Chromium). In the current investigation, the level of ROS and the concentration of MDA as an indicator of lipid peroxide (LPO) were measured in both organs. We picked the two key organs, liver and kidneys, since they are main target organs of damage. Furthermore, the liver is the main organ for xenobiotic biotransformation. ${ }^{(27)}$ As a result, the production of 
ROS causes cellular damage, which may be considered as the common molecular mechanism of hexavalent chromium-induced toxicity. According to this hypothesis, chromium (VI) itself is not a cytotoxic agent but rather an oxygen free radical generator via cellular reduction to chromium (VI). ${ }^{(28)}$ The hydroxyl radical is thought to be formed when chromium reduction intermediates combine with hydrogen peroxide (HO). which may eventually damage biomolecules like proteins, DNA, and membrane lipids, affecting cellular functioning and cell integrity As a result, an antioxidant research of $C$. melo $\mathrm{L}$ fruit aqueous extract indicated that it reduced lipid peroxide by 81 percent in the liver and 77 percent in the kidney when compared to their respective individuals. Therefore, the presence of phytoconstituents present in plant extract are $\beta$-carotenes, multiflorenol, and a range of secondary metabolites, which includes glycolipids, terpenoids, flavonoids, carbohydrates, and apocaretonoids. It possesses several biological properties such as antioxidant, anti-inflammatory, antibacterial, antihypothyroidism, and antiangiogenic activities.

Reduced glutathione (GSH) is commonly found in cells at millimolar concentrations and is known to protect the cellular system from the toxic effects of lipid peroxidation. GSH is important for regulating the cellular redox state ${ }^{(20)}$ and its breakdown is viewed as a sign of oxidative stress. The current study found that $\mathrm{Cr}$ administration changed the levels of antioxidants markers, as measured by a decrease in the amount of reduced glutathione (GSH) in the liver and kidney (significantly decreased at $\mathrm{P}<0.001)$ as compared to the normal control. Excessive oxidative stress may cause soft tissue damage, such as liver and kidney damage. Meanwhile, it was determined that chromium-induced hepatic and renal damage may result from the production of harmful free radicals during the reduction of hexavalent chromium (Cr VI) to trivalent chromium (Cr III) one inside the cell. Most antioxidant enzymes become ineffective after Hexavalent chromiumexposure, either due to direct binding of heavy metals to the SH group of the enzyme active site or due to displacement of metal co-factors from the active site. As a result, the therapy of plant extracts such as Cucumis melo L fruit extracts can regulate the lowered amount of GSH. After treatment with aqueous fruit extracts the level of GSH was significantly increased by $49 \%$ in liver and $60 \%$ in kidney as compared with their respective control rats. Indeed, we suggest that the recommendation of whole fruit is crucially regulating the oxidant and antioxidant imbalance by increasing the level of GSH because that fruit extracts may possess a rich in scavenging activity and high in reducing free radical powers. ${ }^{(29)}$

Free radicals are really eliminated by enzymes such as superoxide dismutase, but the superoxide molecule has the capacity to liberate iron from ferritin, and that free iron interacts with more and more superoxide and hydrogen peroxide to produce very deadly free radicals such as the hydroxyl radical. Hydroxyl radicals are hazardous because they can inactivate some enzymes, including superoxide dismutase, causing lipid peroxidation and DNA strand breaks. As a result, these findings may anticipate a decrease in SOD levels in the liver and kidney, which were significant at $\mathrm{P}<0.001$. Therefore, reduced the level of SOD activity may lead to massive production of the superoxide anion. The production of such anions overrides enzymatic antioxidant activity and leads to a fall in functional concentration in renal and hepatic tissue homeostasis. It was indicated by Siwecka $\mathrm{N}$ et al., $2019^{(30)}$ that most of the antioxidant enzymes become inactive after inducing potassium dichromate exposure, either due to the direct binding of heavy metals to enzyme active site or to the displacement of metal co-factors from active sites. The current findings demonstrate that potassium dichromate therapy caused oxidative stress, as evidenced by a substantial reduction in SOD activity when compared to control values. As a result, the current study investigates the therapeutic efficacy of herbal medicines such as Cucumis melo L fruit extracts in hexavalent chromium poisoning produced in male albino rats. Indeed, our findings show that plant polyphenols may help to restore cellular homeostasis by raising the level of SOD in the liver and kidney by 43 percent and 30 percent, respectively, as compared to their respective control animals. As a result, the beneficial effects of plant extracts on chromium toxicity rats can protect the cell from damage.

The antioxidant enzymes are effective in the cellular primary defense, which prevents biological macromolecules from oxidative injury and removes peroxides, free radicals and superoxide anion, which are all yielded in the inside the cell. The variety of antioxidant enzymes become inactive upon after exposure of $\mathrm{K}_{2} \mathrm{Cr}_{2} \mathrm{O}_{7}$ toxicity. ${ }^{(31)}$ As a result, the current work was aimed to look into the effects of $\mathrm{K} 2 \mathrm{Cr} 2 \mathrm{O} 7$ exposure on the activities of antioxidative defences, namely selenoenzymes like GPx. The reduction of GPx activities in the kidney tissues of the $\mathrm{K}_{2} \mathrm{Cr}_{2} \mathrm{O}_{7}$ group supports these findings, and other studies have shown that inhibition of these enzyme activities is involved in free radical removal, which eventually leads to the accumulation of $\mathrm{H}_{2} \mathrm{O}_{2}$, which promotes lipid peroxidation and DNA modulation, alters gene expression, and ultimately leads to cell apoptosis. ${ }^{(32)}$ However, our recent work shows that Hexavalent chromiumpoisoning reduced the amount of GPx in the liver and kidney by $33 \%$ and $33 \%$, respectively, in male albino rats. As a result, the prescription of plant extracts such as Cucumis melo $\mathrm{L}$ has protective effects against $\mathrm{K} 2 \mathrm{Cr} 2 \mathrm{O} 7$-induced oxidative damage by increasing the level of GPx on the kidney by $27 \%$ and the liver by $20 \%$ of rats. The processes that contribute to its efficacy and the participation of free radical quenching may signify the growing antioxidant defences system. As a result, fruit aqueous extracts appear to play an important role in the defence mechanism against $\mathrm{K}_{2} \mathrm{Cr}_{2} \mathrm{O}_{7}$-induced renal tubular dysfunction and hepatic damage. Indeed, dietary supplementation with plant extracts could be an easy, inexpensive and useful method to combat whoever is exposed to CrVI at workplace from 
its toxic effects.

Catalase protects cells against free radical-induced cytotoxicity. It catalyses the breakdown of $\mathrm{H} 2 \mathrm{O} 2$ into molecular oxygen and H2O. Catalase's important role may limit the effects of oxidant molecules in tissues and act in cellular defence against oxidative cell damage due to its free radical scavenging characteristics. ${ }^{(33)}$ The current findings showed that oral administration of chromium VI led in organ failure, as evidenced by a $25 \%$ decrease in catalase levels in the liver and kidney. As a result, the current findings lead to the conclusion that Hexavalent chromium had detrimental effects via increasing free radicals. As a result, Cucumis melo L demonstrated protective effectiveness against the toxic effects of chromium VI, as evidenced by a rise in different biochemical markers such as catalase, which was raised by the liver (24\%) and kidney (42\%), following treatment with plant fruit extracts.

\section{Conclusion}

Any of the antioxidant capacity assays employed in this study may be employed in assessing the antioxidant capacity of Cucumis spp. fruit extracts. This work suggests that Cucumis melo provides a variety of dietary antioxidants such as flavonoids and ascorbic acid. The results show that the fruit extract at a concentration of $500 \mathrm{mg} / \mathrm{ml}$ protected the animals from the chromium induced oxidative injury significantly. It can be used as safe and effective source of natural antioxidants.

\section{Acknowledgments}

The authors are thankful to Sri Akilandeswari Women's College, Wandiwash for providing the necessary support to carry out this research work

\section{References}

1) Malathi G, Vadivelu J, Rajeshkumar S. Antihyperlipidemic activity of cucumis melo 1 on hexavalant chromium induced male albino rats. International Advanced Research Journal in Science, Engineering and Technology. 2021;8(8):447-455. Available from: https://dx.doi.org/10.17148/iarjset.2021.8875.

2) Wakeel A, Xu M, Gan Y. Chromium-Induced Reactive Oxygen Species Accumulation by Altering the Enzymatic Antioxidant System and Associated Cytotoxic, Genotoxic, Ultrastructural, and Photosynthetic Changes in Plants. International Journal of Molecular Sciences. 2020;21(3):728. Available from: https://dx.doi.org/10.3390/ijms21030728.

3) Machado AB, Caprara JF, de Franceschi ID, Linden R, Berlese DB, Feksa LR. Effects of chronic exposure to hexavalent chromium in water on oxidative stress parameters in Wistar rats. Acta Scientiarum Biological Sciences. 2019;41(1):43771. Available from: https://dx.doi.org/10.4025/actascibiolsci.v41i1. 43771.

4) Ejoh SA, Iheagwam FN, Olusola AO. Potassium Dichromate-Induced Hepato- and Hematotoxicity in Rats: Nutritive Composition and Ameliorative Role of Acacia nilotica L. Leaf. Jundishapur Journal of Natural Pharmaceutical Products. 2021;16(2). Available from: https://dx.doi.org/10.5812/jinpp.104346.

5) Ibrahim DS, El-Maksoud MAA. Antioxidant and antidiabetic activities of Cucumis melo var. flexuosus leaf extract. Indian J Physiol Pharmacol. 2018;62(4):445-452.

6) Kotyk B, Iskra R, Lubunets V. Antioxidant Effect of the Complex Action of Vitamin E and Ethylthiosulfanylate in the Liver and Kidneys of Rats under Conditions of Chrome(VI)-Induced Oxidative Stress. Biointerface Research in Applied Chemistry. 2021;12(2):1405-1420. Available from: https://doi.org/10.33263/BRIAC122.14051420.

7) El-Masry S, Elsayed M. Amelioration of Monosodium Glutamate-induced Testicular Damage and Infertility in Male Rats by Water Melon and Cantaloupe Seeds Extract and Juices. Asian Journal of Research in Biochemistry. 2019;7:1-16. Available from: https://dx.doi.org/10.9734/ajrb/2019/v5i230088.

8) Salehi B, Quispe C, Sharifi-Rad J, Giri L, Suyal R, Jugran AK, et al. Antioxidant potential of family Cucurbitaceae with special emphasis on Cucurbita genus: A key to alleviate oxidative stress-mediated disorders. Phytotherapy Research. 2021;35(7):3533-3557. Available from: https://dx.doi.org/10.1002/ptr.7045.

9) Welz AN, Emberger-Klein A, Menrad K. Why people use herbal medicine: insights from a focus-group study in Germany. BMC Complementary and Alternative Medicine. 2018;18(1):1-9. Available from: https://dx.doi.org/10.1186/s12906-018-2160-6.

10) Pratima H. Antioxidant and antibacterial activity of alkaloid extract of Cucumis trigonus roxb. International Journal of Pharmacy and Pharmaceutical Sciences. 2019;4:44-48. Available from: https://dx.doi.org/10.22159/ijpps.2019v11i4.27071.

11) Martins TEA, Pinto CASDO, Oliveira ACD, Velasco MVR, Guitiérrez ARG, Rafael MFC, et al. Retuerto-Figueroa mg. Contribution of topical antioxidants to maintain healthy skin-A review. Scientia Pharmaceutica. 2020;88(2):27.

12) Ali M, Bilad AL. The role of Cucumic Melo Varieta Agrestis, Vitamin C and Zinc on Sperm Activity and Oxidative Stress during Cryopreservation in Infertile Male. Annals of Tropical Medicine and Public Health. 2019;22:40-44.

13) Rolim PM, Fidelis GP, Padilha CEA, Santos ES, Rocha HAO, Macedo GR. Phenolic profile and antioxidant activity from peels and seeds of melon (Cucumis melo L. var. reticulatus) and their antiproliferative effect in cancer cells. Brazilian Journal of Medical and Biological Research. 2018;51(4):1-14. Available from: https://dx.doi.org/10.1590/1414-431x20176069.

14) Xu J, Zhao M, Pei L, Zhang R, Liu X, Wei L, et al. Oxidative stress and DNA damage in a long-term hexavalent chromium-exposed population in North China: a cross-sectional study. BMJ Open. 2018;8(6):e021470. Available from: https://dx.doi.org/10.1136/bmjopen-2017-021470.

15) Waseem M, Rauf A, Rehman S, Ahmed R. Pharmacognostical and pharmacological review of Cucumis melo L. including Unani medicine perspective. International Journal of Pharmacognosy and Chinese Medicine. 2018;2:1-8. Available from: https://medwinpublishers.com/IPCM/IPCM16000140.pdf.

16) Kushwaha BK, Singh VP. Mitigation of chromium (VI) toxicity by additional sulfur in some vegetable crops involves glutathione and hydrogen sulfide. Plant Physiology and Biochemistry. 2020;155:952-964. Available from: https://dx.doi.org/10.1016/j.plaphy.2020.05.013.

17) Kumar P, Tokas J, Singal HR. Amelioration of Chromium VI Toxicity in Sorghum (Sorghum bicolor L.) using Glycine Betaine. Scientific Reports. 2019;9(1):1-15. Available from: https://dx.doi.org/10.1038/s41598-019-52479-w. 
18) Rajasree RS, Ittiyavirah SP, Naseef PP, Kuruniyan MS, Anisree GS, Elayadeth-Meethal M. An Evaluation of the Antioxidant Activity of a Methanolic Extract of Cucumis melo L. Fruit (F1 Hybrid). Separations. 2021;8(8):123. Available from: https://dx.doi.org/10.3390/separations8080123.

19) Zulfikar M, Widya FS, Wibowo WA, Daryono BS, Widiyanto S. Antioxidant activity of melon fruit (Cucumis melo L. 'GMP') ethanolic extract. In: In AIP Conference Proceedings;vol. 2260. AIP Publishing. 2020;p. 40029.

20) Zhang X, Bai Y, Wang Y, Wang C, Fu J, Gao L, et al. Anticancer Properties of Different Solvent Extracts of Cucumis melo L. Seeds and Whole Fruit and Their Metabolite Profiling Using HPLC and GC-MS. BioMed Research International. 2020;2020:1-9. Available from: https://dx.doi.org/10.1155/2020/5282949.

21) Rajasree RS, Ittiyavirah SP, Naseef PP, Kuruniyan MS, Anisree GS, Elayadeth-Meethal M. An Evaluation of the Antioxidant Activity of a Methanolic Extract of Cucumis melo L. Fruit (F1 Hybrid). Separations. 2021;8(8):123. Available from: https://dx.doi.org/10.3390/separations8080123.

22) Brasili E, Bavasso I, Petruccelli V, Vilardi G, Valletta A, Bosco CD, et al. Remediation of hexavalent chromium contaminated water through zero-valent iron nanoparticles and effects on tomato plant growth performance. Scientific Reports. 2020;10(1):1-1. Available from: https://dx.doi.org/10.1038/s41598020-58639-7.

23) Ravindranath V, Singh J, Jayaprakasha GK, Patil BS. Optimization of Extraction Solvent and Fast Blue BB Assay for Comparative Analysis of Antioxidant Phenolics from Cucumis melo L. Plants. 2021;10(7):1379. Available from: https://dx.doi.org/10.3390/plants10071379.

24) Jana T, Tzveta S, Zlatina N, Natasha I, Dimitrinka A, Milena A, et al. Effect of endurance training on diurnal rhythms of superoxide dismutase activity, glutathione and lipid peroxidation in plasma of pinealectomized rats. Neuroscience Letters. 2020;716:134637. Available from: https://dx.doi.org/10.1016/ j.neulet.2019.134637.

25) Islam R, Sultana B. Research Article Investigation of the Antioxidant Activity in Melon Peel and Seeds (Cucumis melo). JASR. 2020;1(1):1-6.

26) Rolim PM, Fidelis GP, Padilha CEA, Santos ES, Rocha HAO, Macedo GR. Phenolic profile and antioxidant activity from peels and seeds of melon (Cucumis melo L. var. reticulatus) and their antiproliferative effect in cancer cells. Brazilian Journal of Medical and Biological Research. 2018;51(4):6069. Available from: https://dx.doi.org/10.1590/1414-431x20176069.

27) El-Demerdash FM, Jebur AB, Nasr HM, Hamid HM. Modulatory effect ofTurnera diffusaagainst testicular toxicity induced by fenitrothion and/or hexavalent chromium in rats. Environmental Toxicology. 2019;34(3):330-339. Available from: https://dx.doi.org/10.1002/tox.22688.

28) Pereira SC, Oliveira PF, Oliveira SR, de Lourdes Pereira M, Alves MG. Impact of Environmental and Lifestyle Use of Chromium on Male Fertility: Focus on Antioxidant Activity and Oxidative Stress. Antioxidants. 2021;10(9):1365. Available from: https://dx.doi.org/10.3390/antiox10091365.

29) Silva MA, Albuquerque TG, Alves RC, Oliveira MBPP, Costa HS. Melon (Cucumis melo L.) by-products: Potential food ingredients for novel functional foods? Trends in Food Science \& Technology. 2020;98:181-189. Available from: https://dx.doi.org/10.1016/j.tifs.2018.07.005.

30) Siwecka N, Rozpędek W, Pytel D, Wawrzynkiewicz A, Dziki A, Dziki Ł, et al. Dual role of Endoplasmic Reticulum Stress-Mediated Unfolded Protein Response Signaling Pathway in Carcinogenesis. International Journal of Molecular Sciences. 2019;20(18):4354. Available from: https://dx.doi.org/10.3390/ ijms20184354.

31) Nwachukwu ID, Sarteshnizi RA, Udenigwe CC, Aluko RE. A Concise Review of Current In Vitro Chemical and Cell-Based Antioxidant Assay Methods. Molecules. 2021;26(16):4865. Available from: https://dx.doi.org/10.3390/molecules 26164865 .

32) Renu K, Chakraborty R, Myakala H, Koti R, Famurewa AC, Madhyastha H, et al. Molecular mechanism of heavy metals (Lead, Chromium, Arsenic, Mercury, Nickel and Cadmium) - induced hepatotoxicity - A review. Chemosphere. 2021;271:129735-129735. Available from: https://dx.doi.org/10. 1016/j.chemosphere.2021.129735. doi:10.1016/j.chemosphere.2021.129735.

33) Li Q, Gao Y, Shen J, Mu X, Wang J, Ouyang L, et al. Catalase-like quantum dots of l-lysine polymerization as free radical scavengers for hypoxic brain injury. Materials Today Communications. 2021;27:102286. Available from: https://dx.doi.org/10.1016/j.mtcomm.2021.102286. 